\title{
DECADE-TO-CENTURY CHANGES IN THE OCEAN CiRCULATION
}

\author{
By Carl Wunsch
}

T HE ORIGINS of this note lie in an invitation from Dr. Lynne Talley to speak at the second meeting of The Oceanography Society regarding climate change in the ocean on time scales of decades to about 100 years. In reviewing the literature, I was increasingly struck by how little could actually be said about known changes. Here I would like to summarize the situation and at the end to briefly discuss what we might do about future changes.

One can usefully start by asking a few questions: (1) Do we expect decadal-scale oceanic changes? (2) If so, can we expect to have observed them? (3) Do we in fact observe anything? (4) If we observe anything, can we interpret it?

\section{Are Changes Expected?}

The ocean is a turbulent fluid in intimate contact with another turbulent fluid, the atmosphere. Although I am unaware of any formal theorems on the subject, experience with turbulent systems suggests that it is very unlikely that any components of such a complex nonlinear system can actually remain fully steady. Consider that should we be able to identify any frequencies or wavenumbers of the oceanic circulation that did not change with time, that we would have found that Holy Grail of turbulence theory - the spectral gap. The identification of a spectral gap would be an immensely powerful theoretical tool and would be one of the most important oceanographic discoveries of the century. But the coupled ocean/ atmosphere system is much too complex to expect zero-energy elements at any scales: the frequency/ wavenumber spectrum of the ocean circulation is almost surely everywhere filled. These fluctuations are the "natural variability": any human-induced changes would appear superimposed upon them.

Why then does the oceanographic literature have so many papers expressing surprise when some element of the circulation appears to be changing? Probably because the observational necessity of the past 100 years dictated a particular

C. Wunsch, Department of Earth, Atmospheric, and Planetary Sciences, Massachusetts Institute of Technology. Cambridge, MA 02139. USA mind-set: observing the ocean is so difficult that oceanographers necessarily resorted to treating data taken over many years and decades as though it were simultaneous. Much has been learned this way; but in the process there has been a tendency to lose sight of the fact that a steady-state ocean had been assumed-and not demonstrated. Indeed to the contrary, expressions of surprise ought to be reserved for a determination that something has not changed over some time interval [e.g.. the recent 3-year results of Dickson et al. (1990) for the North Atlantic overflows].

\section{Do We Observe Anything?}

The instrumental record of ocean circulation is barely 100 years long. There are continuous records over the past 100 years of almost nothing except a few tide-gauge records. Hydrography has been sporadic in both space and time. Figure 1 shows some of Levitus' (1988) compilation of hydrographic observations to 1,000 meters and the observation levels through time. Perhaps readers do not need to be reminded that 1,000 meters covers a small fraction of the water column and that plots similar to Levitus' showing full watercolumn coverage would be almost completely blank until very recently.

We are sure that some things have not changed: the Gulf Stream was there 100 years ago, as was the Kuroshio, the thermocline, and many other qualitatively important elements of the circulation. But what can be said to have changed?

Levitus (1989) discusses apparent changes in the North Atlantic over about 15 years, and Roemmich and Wunsch (1984) documented an apparent change over about 23 years. Two points should be made: some change will always be found if only because the data distributions differ at the two time periods being used, and because in many cases an instrument change (Nansen bottles and reversing thermometers to STDs and CTDs) took place. Both sampling distributions and differing error budgets will necessarily produce changes. Determining the levels of significance of these changes is not easy.

The second comment is that studies like Levitus' are probably impossible except in the North
. . expressions of surprise ought to be reserved for a determination that something has not changed. . . 


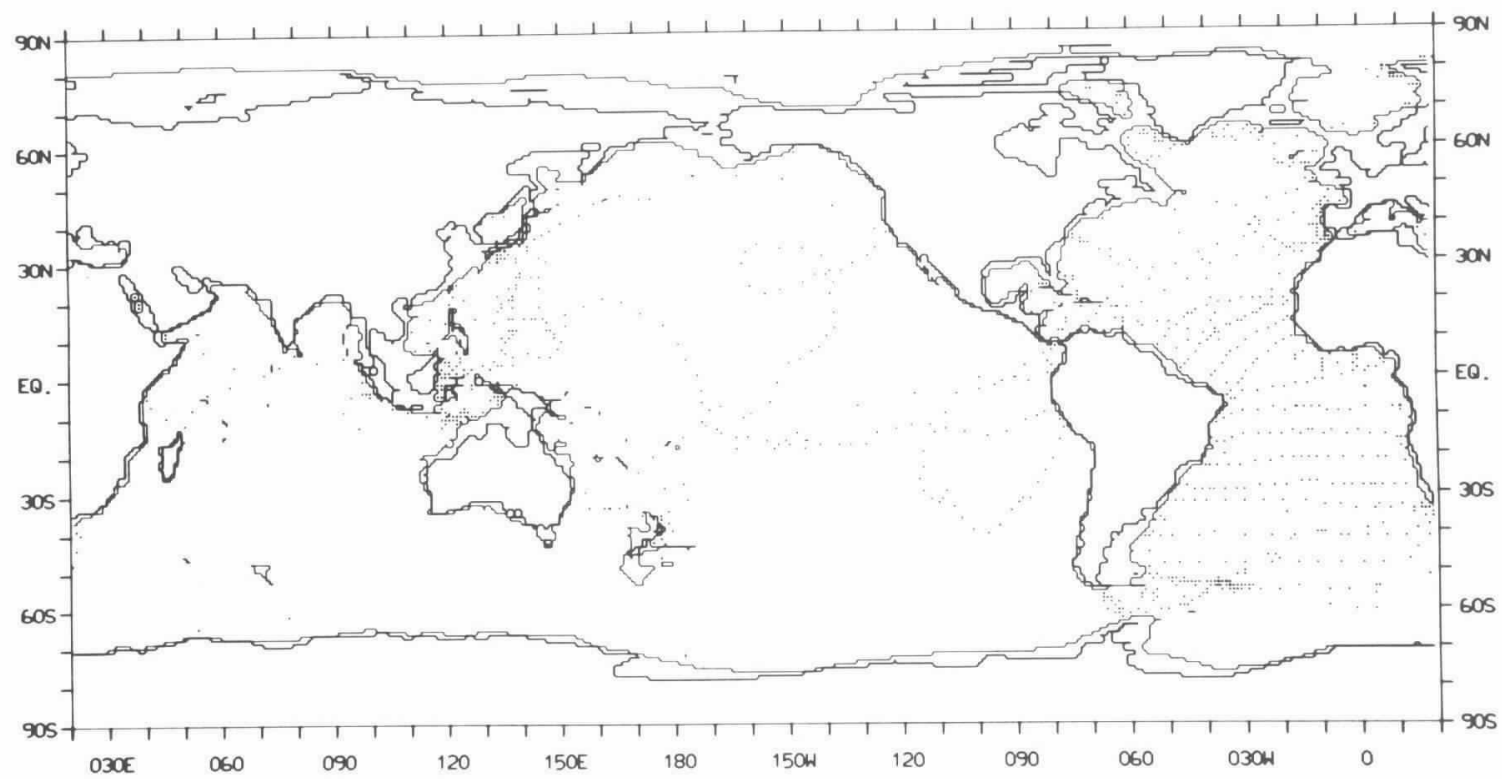

(A)

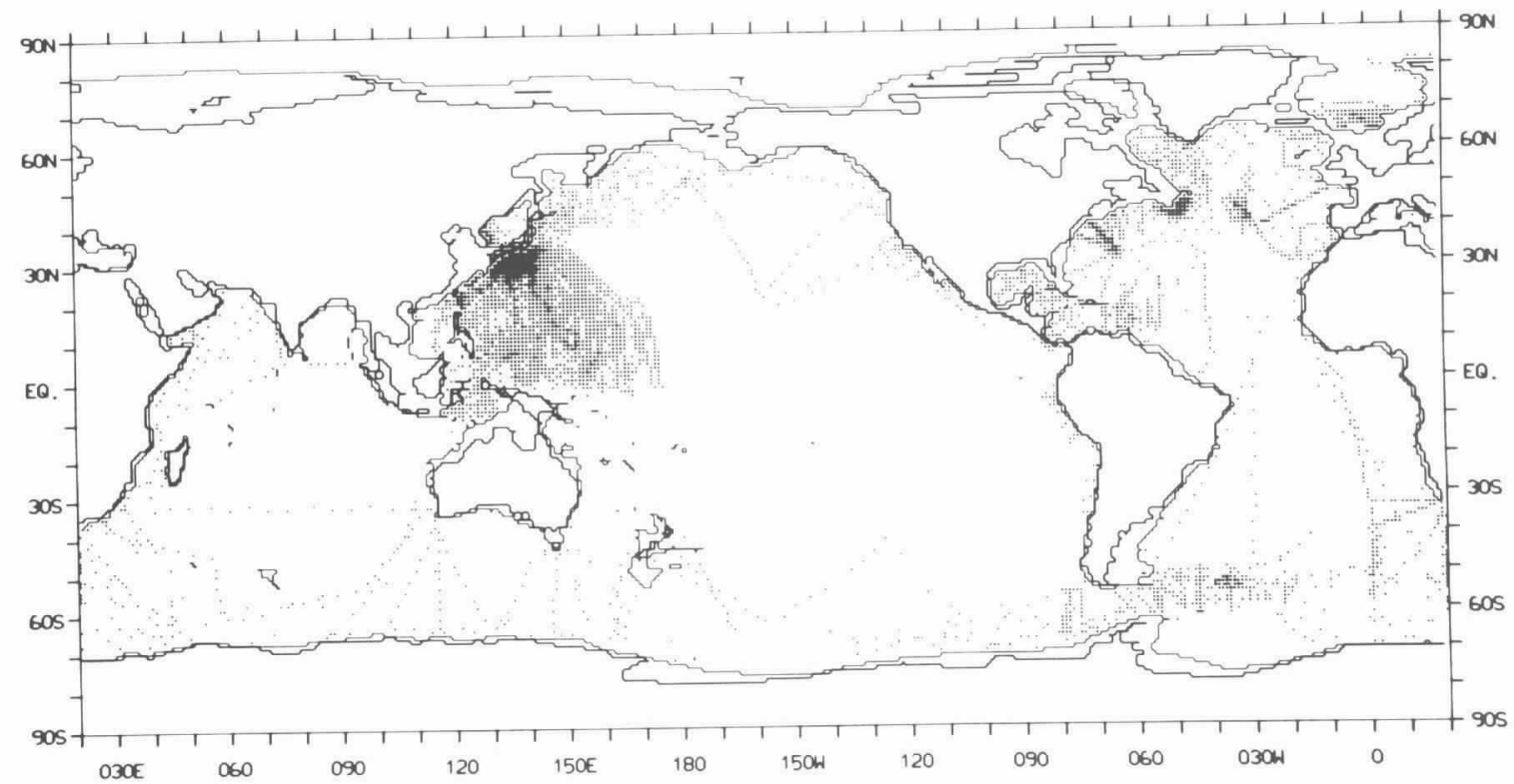

(B)

Fig. 1: (A-C) Hydrographic data to 1000 meters, as compiled by Levitus (1988) showing the distribution in the decades 1920-1929, 1930-1939, and 1940-1949. This extremely sparse distribution, covering only a fraction of the water depth, is all we have to determine the changing interior structure over the past 70 years and is grossly inadequate even in the upper ocean, given the very large mesoscale variability. Data coverage below 1,000 meters is much worse. (D) Changing numbers of hydrographic stations

... sought changes

over time in the

estimated meridional

flux of heat but found

nothing significant. reaching to 1,000 meters through time. The diminishing coverage soon after the arrival of STDs and CTDs (mid-1970s) is striking.

Atlantic and conceivably in the western Pacific near Japan. Repeated section studies such as that of Roemmich and Wunsch (1984) are possible in a few places, e.g., Fu (1981) in the South Atlantic used the Meteor (mid 1920s) lines and the IGY lines (1958). Both these papers sought changes over time in the estimated meridional flux of heat but found nothing significant. In other oceans, there are few available transoceanic lines (the South Pacific Scorpio lines and the dense hydrog- raphy of the Southern Ocean all date from around 1970), precluding any time-difference studies except over the past 20 years, should anyone trouble to repeat the lines. Bindoff and Wunsch (1991) estimated the smallest possible hydrographic change that could be detected in the tropical South Pacific by comparing a hypothetical modern CTD line with a difference computed from historical data. They concluded that at 2,000 meters a mean vertical migration of an isotherm of 50 meters, 


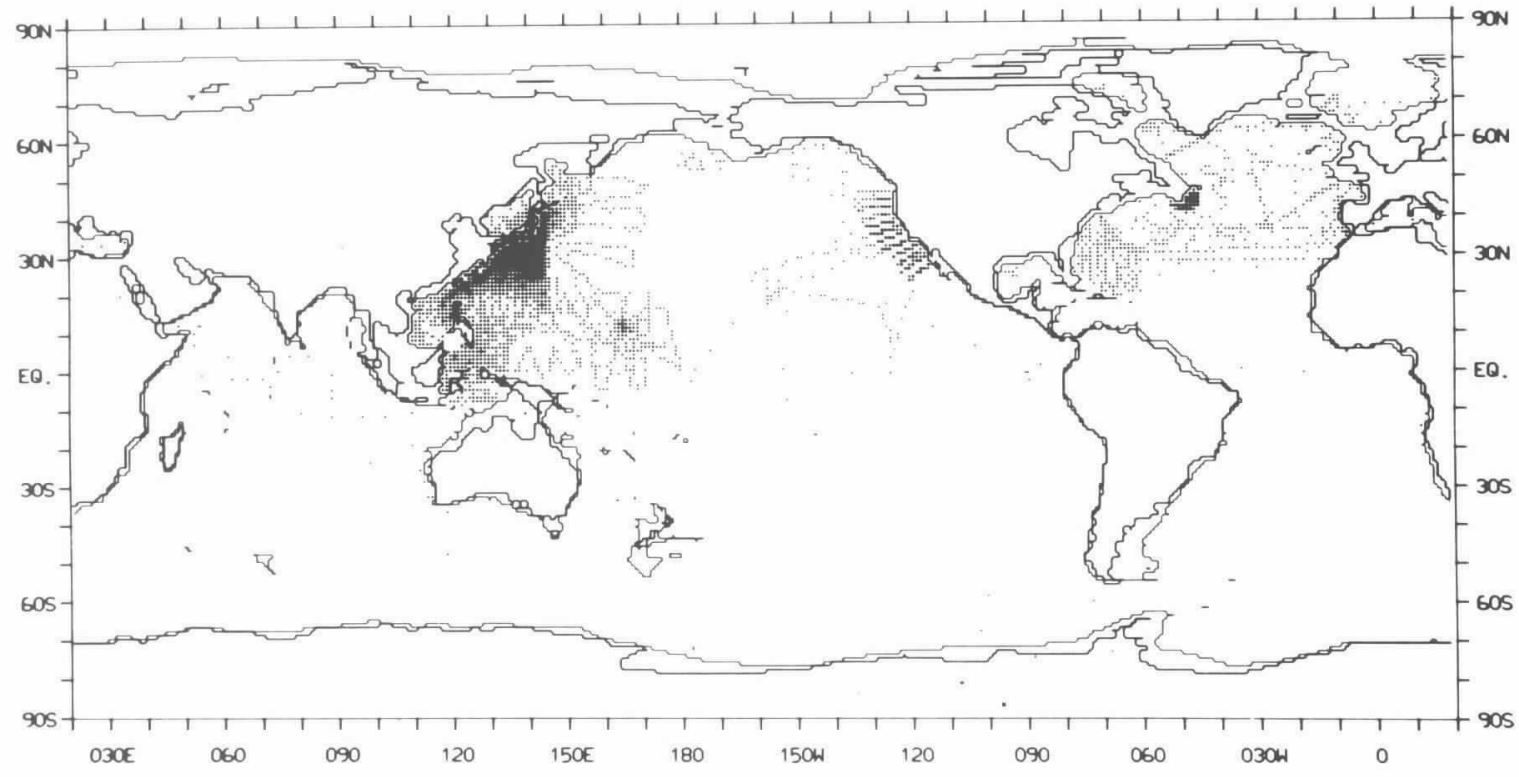

(C)

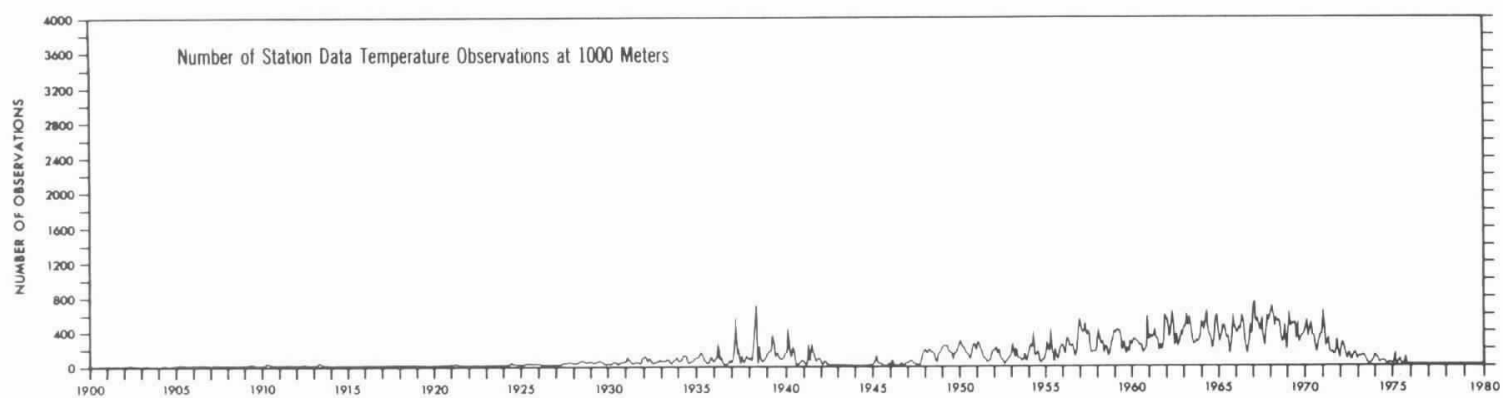

(D)

Fig. 1: Continued

over the whole width of the ocean, would have to occur before it could be deemed significant. At 800 meters, the shift would have to be 25 meters. Such changes are very large and have never been observed. The main problem is the very poor historical coverage, which effectively prevents us from detecting any climatic shifts of oceanic hydrography.

Barnett (1984), Douglas (1991), and others have used tide gauge records to infer large-scale patterns of sea level change. Although there is a tentative consensus that a global increase in sea level is occurring, the subject remains fraught with grave difficulties, which arise from at least two major causes: (1) the tectonic and glacial rebound corrections are large and controversial, and (2) the distribution of tide gauges around the world is very poor for determining a global average. This problem is obvious in the monthly Pacific sea level maps distributed by the University of Hawaii Sea Level Center. The gauges in the Pacific basin are far from homogeneously distributed and reside in flow regimes of radically different character e.g., western boundary currents, eastern boundary currents, the tropical circulation. There is no rea- son to think that sea level changes need even be of the same sign everywhere much less show some simple, global, monotonic signal. Indeed, fluctuations in the circulation patterns could well force lowered sea level in some areas.

Bottomley et al. (1990) have produced a compilation of sea surface temperatures on a global basis. This study is simultaneously interesting and rather sad. It is interesting to see that there are apparent large-scale patterns and trends. It is sad, however, to see that one is driven to strange and not very convincing studies of corrections for shifts from canvas to metal buckets, from buckets to engine intake temperatures. These are the lengths to which one must go to extract anything from the past record, and the result is no more than suggestive of possible change.

What else is there to look at? The Panulirus record (Station $\mathrm{S}$ ) extends almost 40 years now, the longest such record known to me. It sits in the middle of the North Atlantic subtropical gyre, where one might expect that secular trends in oceanic conditions would appear last. The measurements extend to roughly 1,500 meters and were subject to interruptions and calibration
The main problem is the very poor historical coverage, which effectively prevents us from detecting any climatic shifts. . . 
. . counter-intuitive

effects possible in a

system with a simple

long-term memory. problems. No other record remotely as good exists for studying decadal scale changes. Cardone et al. (1990) showed that we cannot even trust decadal trends in wind measurements in the open ocean.

There is one decadal scale change which is incontrovertible. There are chemical tracers in the ocean now that were not there 30,50 , and 100 years ago. That there is tritium and fluorocarbon on the floor of the oceans within one or two decades of the atmospheric increase is obvious (e.g., Ostlünd and Rooth, 1990). Nonetheless, we do not see the supposed increase in oceanic $\mathrm{CO}_{2}$ that is so obvious in the atmosphere (e.g., Siegenthaler and Oeschger, 1987) — the data base is hopeless for that purpose.

Other isolated bits of information are available, e.g., coral isotope records and the Koch index of sea ice density near Iceland. These records are interesting and again suggestive. But they are restricted to special, often isolated, regions of the ocean and are not always readily interpretable.

My summary so far would be that we expect the ocean to be changing; we have fragments of evidence that the system does indeed fluctuate on all space and time scales. But the past record is woefully inadequate to document anything on a large regional scale, much less globally. Determining whether the ocean is in a statistical equilibrium or undergoing secular shifts is impossible.

Could We Interpret Change If We Saw It?

Here one needs to be careful because it is dangerous to claim that something cannot be done. I wish merely to raise some warning flags.

Hasselmann (1976) and Frankignoul and Hasselmann (1977) have pointed out the somewhat counter-intuitive effects possible in a system with a simple long-term memory. But the message seems not to be widely appreciated. Consider the record shown in Figure $2 \mathrm{~A}$. To me, it looks much like a multitude of oceanographic records, temperature, or a component of velocity, for example. For comparison, I show in Figure 3A the 2-year record of transport fluctuations in the Straits of Florida (from Schott et al., 1988), and in 3B, the salinity anomaly of water in Rockall Channel (from Ellett and MacDougall, 1983). To the eye, these observations are rather similar in character to the record in Figure 2A, although the reader should notice that the timescale on Figure 2A is deliberately without units.

Figure 2A was generated by simply forming the cumulative sum of the "forcing" in Figure 2B; i.e., by summing white noise as

$$
\begin{aligned}
\mathrm{y}(\mathrm{t}) & =\sum_{\mathrm{t}^{\prime}=0}^{\mathrm{t}} \xi\left(\mathrm{t}^{\prime}\right) \\
\langle\xi(\mathrm{t})\rangle & =0, \quad\left\langle\xi(\mathrm{t}) \xi\left(\mathrm{t}^{\prime}\right)\right\rangle=\sigma_{\theta}^{2} \delta_{\mathrm{tt}^{\prime}}
\end{aligned}
$$

where the bracket denotes the expected value, and $\mathrm{t}=\cdots-1,0,1,2, \cdots$ is time. Such an accu-

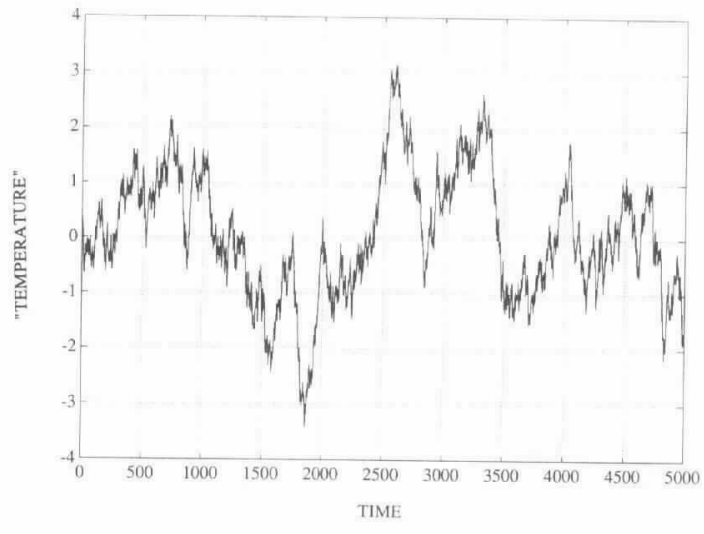

(A)

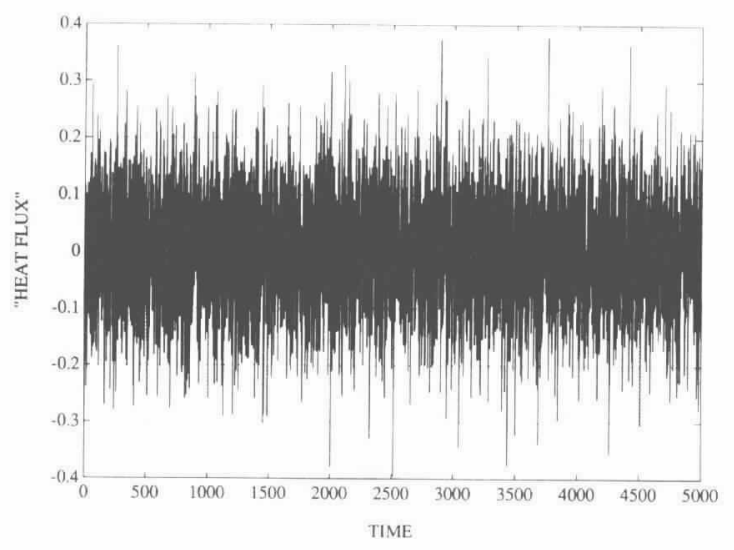

(B)

Fig. 2: (A) A synthetic time series constructed using equation (1) and the white noise shown in B. Although labeled "temperature," it mimics many oceanic time series. Such a sequence has an expected value of zero, but has a variance increasing with time, is not stationary, and has a sample average whose variance also grows with record length. (B) "Forcing" used to generate the time series in $A-a$ pseudo-random sequence, labeled "heat flux" to mimic an analogue "temperature" shown in $A$, possibly driven by purely random heat exchanges with the atmosphere.

mulating sum is a special case of a first-order autoregressive process, AR, of form

$$
\mathrm{y}(\mathrm{t})=\operatorname{ay}(\mathrm{t}-1)+\xi(\mathrm{t})
$$

with $\mathrm{a}=1$. Such a process has a zero mean, but a variance

$$
\left\langle\mathrm{y}(\mathrm{t})^{2}\right\rangle=\sigma_{\theta}^{2} \mathrm{t}
$$

(see for example, Priestley, 1981, Chapter 3), i.e., unbounded with $\mathrm{t}$.

If $\xi(t)$ is restricted to the values \pm 1 , e.g., obtained by flipping a simple coin, then $y(t)$ is known as the "Game of Peter and Paul": if the coin is heads, Peter pays Paul a dollar, and if tails Paul pays Peter. $y(t)$ represents Paul's net earnings at 


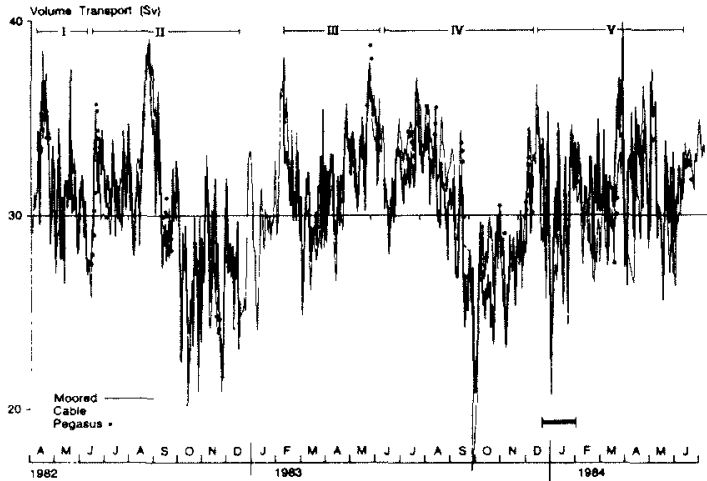

(A)

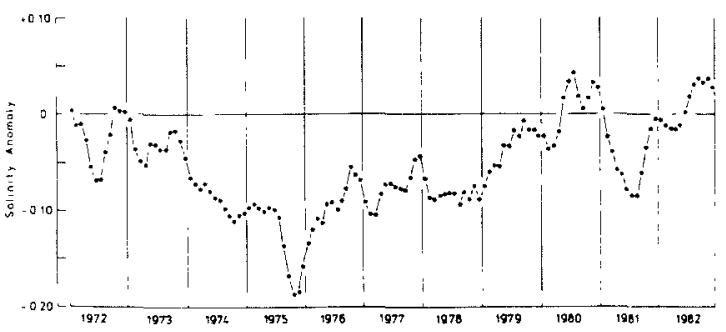

(B)

Fig. 3: (A) Estimates of the mass flux through the Florida Straits over a roughly two-year period (Schott et al., 1988). Visually, the record is similar to that in Figure $2 A$, perhaps because the Florida Current mass transport is a summation of small effects distributed over the entire ocean. (B) Salinity anomaly in Rockall Channel (from Ellett and MacDougall, 1983; reproduced by Dickson et al., 1988).

time t. Quite contrary to intuition, it is very improbable that the time series is near its true mean of zero. Rather the time series spends most of its time far from the breakeven point, and the swings get arbitrarily large as $t \rightarrow \propto$. Feller (1957, Chapter III) has an interesting account of the unexpected properties of the Game of Peter and Paul. Consider that the sample average of $y(t)$,

$$
\bar{y}(N) \equiv\langle y(t)\rangle_{N}=\frac{1}{N} \sum_{t=0}^{N} y(t)
$$

has a variance about the true mean of

$$
\left.\mathrm{D}^{2}(\overline{\mathrm{y}}(\mathrm{N})) \equiv\left\langle\overline{\mathrm{y}}_{\mathrm{N}}-\langle\mathrm{y}(\mathrm{t})\rangle\right)^{2}\right\rangle \rightarrow \sigma_{\theta}^{2} \mathrm{~N} / 2
$$

for large N. What this means is that unlike most familiar processes the sample average does not converge (in probability) to the true mean: no matter how much data we obtain, the variability of the sample average actually grows.

The spectrum of $y(t)$ is shown in Figure 4. It is "red" like most geophysical spectra because it continues to increase toward low frequencies. The spectrum is indistinguishable from that of many real oceanographic records. Consider by way of further example that Zenk and Müller (1988) failed to find a significant mean in a 7-year-long current record. Perhaps in view of Figures 2 and 4 , this result is unsurprising.

Now we do not expect that the ocean has the infinite memory of the Game of Peter and Paul rather $|\mathrm{a}|<1$, but the ocean clearly has some extremely long-lived memories of past eventsat least hundreds and perhaps thousands of years. (Is current sea level rising because the ocean is recovering from the Little Ice Age?) On the time scale of decadal change, the memory may be effectively infinite, a indistinguishable from 1 . The record may be without measurable mean but with a growing variance, a red spectrum, nonstationarity and generally self-similar character (i.e., fractal). All these things are a consequence of the long memory and the simple model (Eq. 2).

This example may appear overly simple to the reader. To see equivalent behavior in a much more complex system consider Figure 5 taken from Mikolajewicz and Meier-Reimer (1990). They forced a global general circulation model to a steady state with realistic winds and thermo-
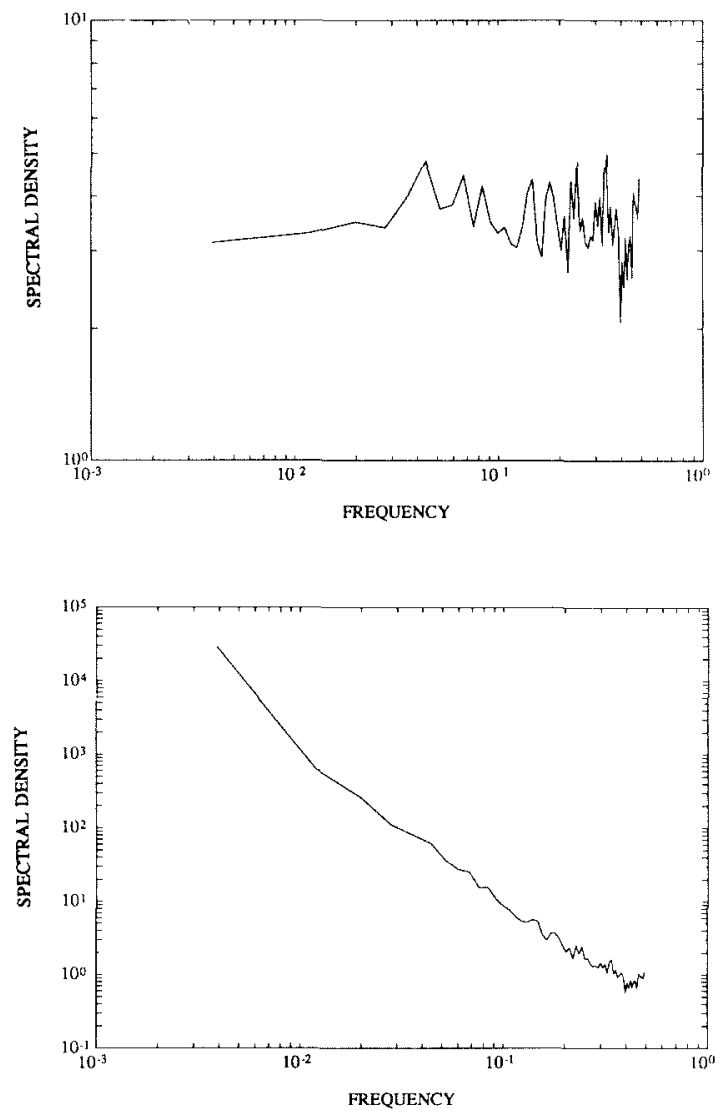

Fig. 4: Spectral estimate of time series in Figure $2 B$ (top), and $2 A$ (bottom). The latter displays characteristic "red" structure of many oceanographic time series.
Is current sea level rising because the ocean is recovering from the Little Ice Age? 

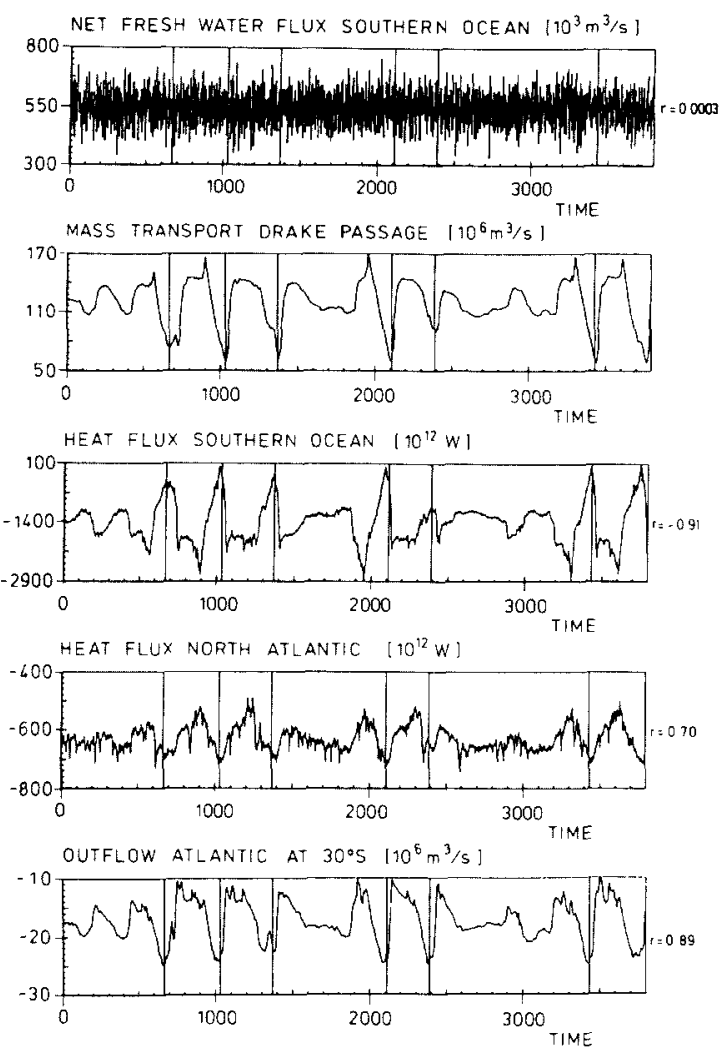

Fig. 5: Results from a numerical experiment performed by Mikolajewicz and Maier-Reimer (1990). A model which had reached a near steadystate condition was driven by a white noise input of buoyancy in the Southern Ocean (top panel) (the forcing was white in time, but roughly uniform over regions of order $25^{\circ}$ on a side). The model responded by generating large fluctuations in the Drake Passage mass flux and several other integrated properties. Although the time scale (in years) is not decadal, the principle-accumulation of uncorrelated forcings leading to wide swings in a system with memory-is identical to that described in the text.

to do so that our

successors . . . will

not be in the same

helpless position. . . necessarily caused by such purely random processes. But we should be wary of facile arguments that there are necessarily simple identifiable cause and effect relations between what we see in the ocean and secular changes in the atmosphere. Consider once again the fluctuations of the Florida Current in Figure 3A. Are these fluctuations due to (as many have attempted to show) large-scale fluctuations in the wind field over the North Atlantic? It is quite possible, and efforts to understand such a cause and effect should continue. But what else might be going on? Suppose, just by way of example, local instabilities of the Gulf Stream become slightly more active for a few years, generating one or two extra warm or cold core rings per year. Suppose the internal instabilities of the equatorial current system weaken slightly. Could such internally generated whitenoise-like instability processes sum to produce fluctuations in the Florida Straits like those observed? The Game of Peter and Paul suggests the answer is "yes." Could the fluctuations be caused by a large-scale change in the intensity of the North Atlantic wind-stress curl? Again, the answer is "yes."

\section{What Should We Do?}

To summarize again, we have seen that changes in the ocean on decadal and longer scales are expected; we have little or no data to show precisely what those changes have been in the past 100 years; to the extent that we do see changes, they may be unrelated to simple large-scale changes in the atmosphere. They could arise either as summations of essentially random nearly unpatterned atmospheric fluctuations or through wholly internal fluctuations generated by oceanic instabilities.

The question I would now raise is what do we need to do so that our successors in 2041, looking back toward 1991, will not be in the same nearly helpless position as we are looking back to 1941 ? This is a question of observational strategy-a large and interesting problem. I have only a few comments about it based upon some of the results above, and from involvement in the design and completion of the World Ocean Circulation Experiment (WOCE).

The generation of an observing system capable of both describing and permitting understanding of large-scale changes is a complex amalgam of insight and investment into technology. The characteristics of such a system that seem critical are continuity and coverage. True climate change, which as we have seen is hard to describe, might be defined as a large-scale secular trend. The determination of weak trends in noisy systems is difficult at best: it becomes nearly impossible unless the observations employed are continuous (e.g., Station $\mathrm{S}$ is difficult to analyze because of the intermittent gaps which appear in it). Second. 
a system must be global. The difficulties of computing baroclinic changes in the ocean, given the scatter of hydrography in Figure 1, are plain.

This last point is perhaps worth belaboring a bit. Many oceanographers, both theoreticians and observers, have been attracted to observational strategies based upon the "choke point" notion. The idea is that places like the Drake Passage and the Florida Straits are easy to observe and that they sum effects which might represent true climate variability. Such measurements are worthwhile and interesting. But the simple examples in Figures 2 and 5 ought to undermine any notion that such observations by themselves could conceivably ever be adequate. One might observe fluctuations such as those of the Florida Current. but one would have no way of distinguishing the purely random summation character of the flow through them from some much larger broader scale changes taking place in the ocean or the atmosphere as a whole. A pure "choke-point" strategy is doomed from the outset by its most attractive feature-its natural integrating nature.

What can we do? There are two distinct aspects. We could attempt to produce a baseline now, so that large-scale studies of change over decades could be made in the future against a reference in the early 1990s. The papers already cited have shown the efficacy of the repeat hydrographic-line strategy. At the very least, we could by carrying out a large-scale survey of how the ocean looks in the $1990 \mathrm{~s}$, provide a baseline to which oceanographers of the 2040 s could refer. Some of the rationale for the WOCE hydrographic survey is based upon the necessity of documenting the present thermochemical state of the ocean for future use.

But the ability to use the WOCE surveys of $1991+$ in the years to come is clearly an incomplete basis on which to march into the future. The WOCE surveys cannot be repeated every 5 or 10 years: the ship and human resources are inadequate to sustain such an effort. One might envision it being done again, perhaps, in $2041+$ by the shipborne technology of that era. But surely no one would repeat it on the 5-10-year basis, which appears minimal to track the system as it evolves.

Similarly, while TOGA, WOCE, and other programs are maintaining and augmenting the existing tide-gauge network, the maldistribution of islands and suitable harbors is not addressed by adding a few more gauges to follow sea level evolution. Minor additions to the volunteer ship fleet doing xbt's of the upper ocean will likewise never address the real need. The upper 1,000 meters (i.e., at best what xbt's can examine), even if the volunteer fleet produced uniform global coverage, cannot address the fact that the entire water column must be observed before one could hope to understand decadal changes and climate. The existing traditional observing systems remain necessary for the near-term; they are plainly inadequate for the long term.

If we agree that decadal and 100-year-scale oceanic changes are of interest, then we must think about the technologies we need. Without claiming to be all encompassing, I would argue that the following are necessary.

1. Cheap, reliable telemetry. Munk and Wunsch (1982) described the limitations of the current observational systems, which are based upon "going and fetching"-either going and fetching a particular observation or going and fetching instruments to obtain the recorded data. Such a system will fail to provide adequate future coverage. We need to solve the telemetry problem both within the water column (getting data to the surface from in situ instruments 5,000 meters deep) and from the water surface back to the laboratory. Several such schemes are under development; a major push is needed.

2. Unmanned profiling devices. Although a global survey by ship can be contemplated and justified every few decades, it is a hopeless way to sample the ocean on a 5 -year or more frequent basis (as already noted). Several groups are developing unmanned top-to-bottom profiling devices. Which will prove best in the long-run, I do not know. But we must collect the data in some manner.

3. Satellites. The arguments for using satellites are so obvious that I will not repeat them here. Active microwave devices, in particular, have shifted from the oceanographic curiosities that they have been, until very recently, to central observation systems that must be maintained in an operational mode, as is done with meteorological satellites.

4. Acoustics. Oceanographers have tended to shy away from the inexorable conclusion that only acoustics can play the role in measurements of the ocean that electromagnetic radiation plays in the remainder of fluid dynamics, including the atmosphere. We cannot use electromagnetic radiation to send or receive information to our instruments or to probe the system. We know that we can use sound, both for straight telemetry, for tracking, and for direct probing. There is no substitute, and the investment needs to be made sooner rather than later.

\section{Summary}

I would summarize this discussion by the following simple statements.

1. Decadal and longer-scale changes in the ocean are expected; fragmentary evidence of their existence is available.

2. The historical data base is inadequate to ever produce more than suggestive evidence.

3. For purposes of understanding global climate change, the most urgent priority is to provide can play the role in

measurements of the

ocean that

electromagnetic

radiation plays in the

remainder of fluid

dynamics . . . 
.. without a detailed

knowledge of the

natural variability, the

determination of

climatic trends is nearly

impossible. a data base that future generations will be able to employ to distinguish very large-scale secularities from regional nonsecular fluctuations. In other words, without a detailed knowledge of the natural variability, the determination of climatic trends is nearly impossible.

4. The technology to provide such a data base differs from that of conventional oceanographic tools but appears to be available to us. The will to deploy it is required.

\section{Acknowledgements}

This research was supported in part by the National Science Foundation under Grant OCE8823043 and the National Oceanic and Atmospheric Administration under Grant NA90AA-D-AC506. This paper represents a contribution from the World Ocean Circulation Experiment.

\section{References}

Barnett, T.P., 1984: The estimation of "global" sea level change: a problem of uniqueness. $J$. Geophys. Res., 89,79807988.

Bindoff, N. and C. Wunsch, 1992: Comparison of synoptic and climatologically mapped sections in the South $\mathrm{Pa}$ cific Ocean. J. Climate. 5. 615-629.

Bottomley, M., C.K. Folland. J. Hsiung, R.E. Newell and D.E Parker, 1990: Global Ocean Surface Temperature Atlas. "GOSTA" A Joint Project of the Meteorological Office and Massachusetts Instiute of Technology'. The Met Office, 20pp. and 313 Plates.

Cardone, V.J. J.G. Greenwood and M.A. Cane, 1990: On trends in historical marine wind data. J. Climate. 3 113-127.

Dickson, R.R., J. Meincke, S.-A. Malmberg and A. Jake, 1988 The great salinity anomaly. Prog. in Oceanogr., 20, 103151.

, E.M. Gmitrowicz and A.J. Watson, 1990: Deep-water renewal in the northern North Atlantic. Nature, 334 $848-850$.

Douglas, B.C.. 1991: Global sea level rise. J. Geophys. Res. 96. 6981-6992.

Ellett, D.J. and N. MacDougall, 1983: Some monitoring results from west of Britain. Technical Series, Intergovernmental Oceanographic Commission, UNESCO, 24, 2125.

Feller, W., 1957: An Introduction to Probability Theory and Its Applications, 2nd ed. Wiley, New York. $461 \mathrm{pp}$.

Frankignoul, C. and K. Hasselmann, 1977: Stochastic climate models. Part II. Application to seasurface temperature temperature anomalies and thermocline variability. Tellus, 29, 289-305.

$\mathrm{Fu}$, L., 1981: The general circulation and meridional heat transport of the subtropical South Atlantic determined by inverse methods. J. Phys. Oc., 11, 1171-1193.

Hasselmann. K., 1976: Stochastic climate models. Part 1. Theory. Tellus, $28,473-485$.

Levitus, S., 1988: Decadal and pentadal distributions of hydrographic stations at $1000 \mathrm{~m}$ depth for the world ocean Prog. in Oceanog., 20, 83-101.

1989: Interpentadal variability of temperature and salinity in the deep North Atlantic, 1970-74 versus 1955-1959. J. Geophys. Res., 94, 16,126-16,131, (see correction, J. Geophy's. Res., 94, p. 14,599).

Mikolajewicz, U. and E. Maier-Reimer, 1990: Internal secular variability in an ocean general circulation model. Climate Dyn., 4, 145-156.

Munk, W. and C. Wunsch, 1982: Observing the ocean in the 1990s. Phil. Trans. Roy. Soc. A, 307, 439-464.

Östlund, H.G. and C.G.H. Rooth, 1990: The North Atlantic tritium and radiocarbon transients 1972-1983. J. Geophys. Res., 95, 20,147-20,165.

Priestley, M.B., 1981: Spectral Analysis and Time Series. Iolume 1: Univariate Series. Folume 2: Multivariate Series, Prediction and Control. Academic, London. $890 \mathrm{pp}$ plus appendices (combined edition).

Roemmich, D. and C. Wunsch, 1984: Apparent change in the climatic state of the deep North Atlantic Ocean. Nature. $307,447-450$.

Schott, F.A., T.N. Lee and R. Zantopp, 1988: Variability of structure and transport of the Florida Current in the period range of days to seasonal. J. Phys. Oc., 18,1209 1230.

Siegenthaler, U. and H. Oeschger, 1987: Biospheric $\mathrm{CO}_{2}$ emissions during the past 200 years reconstructed by deconvolution of ice core data. Tellus, 39B, 140-154.

Zenk, W. and P. Müller, 1988: Seven-year current meter record in the eastern North Atlantic. Deep-Sea Res., 35. 12591268. 